\title{
A comparison of endovenous laser ablation and conventional surgery in patients with varicose veins of the lower limbs
}

\author{
Linas Velička', Mantas Kievišas ${ }^{2}$, Vytenis Keturakis ${ }^{2}$ \\ 'Department of Cardiothoracic and Vascular Surgery, Lithuanian University of Health Sciences, Kaunas, Lithuania \\ ${ }^{2}$ Faculty of Medicine, Lithuanian University of Health Sciences, Kaunas, Lithuania
}

\begin{abstract}
Introduction. Even though EVLA is increasingly popular and together with other minimally-invasive techniques is rapidly replacing surgical stripping, surgical treatment is still widely used. Our study aimed to compare the clinical outcomes and the quality of life following either endovenous laser ablation (EVLA) or conventional surgery for varicose veins of the lower limbs.
\end{abstract}

Material and methods. This prospective non-randomised study included 299 patients, who were treated for symptomatic varicose veins of the lower limbs in two centres. In one, 159 patients underwent open surgery (the surgery group), while in the other, 140 patients received the EVLA (the EVLA group). The patients were invited to follow-up evaluations at six weeks, one year, and two years after the surgery.

Results. Disease-specific quality of life at six weeks was significantly better in the EVLA group (median AWQ scores - $3.2(2.1-8)$ vs. $9.2(7.1-13.8), p<0.001)$. Similarly, VCSS scores at six weeks were also better in the EVLA group (median VCSS scores - I (0-2) vs. $4(3-6), p<0.001$ ). Patients in the EVLA group experienced less postoperative pain $(p<0.001)$, and therefore needed fewer supplementary analgesic drugs $(p=0.007)$. In addition, patients in the EVLA group managed to return to work and normal activities sooner than those in the surgery group $(p<0.001)$. No statistically significant differences were found between groups for clinical recurrence, overall satisfaction, rate of complications and secondary procedures.

Conclusions. Both treatment techniques yielded similar results in terms of efficacy, clinical recurrence rates and overall patient satisfaction. However, early postoperative results in the EVLA group were superior to those of patients in the surgery group.

Key words: varicose veins, endovenous laser ablation (EVLA), open surgical treatment, quality of life, Aberdeen Varicose Vein Questionnaire (AWQ), Venous Clinical Severity Score

Acta Angiol 2015; $21,4: 107-115$

\section{Introduction}

Varicose veins in the lower extremities is one of the most common diseases affecting $10-20 \%$ of the adult population [I]. The prevalence of the pathology increases with age - from $12 \%$ in the age group of $18-$ -24 years to $56 \%$ in individuals aged $55-64$ years [2]. Having regard to the ageing of the human population, in several decades this disease is predicted to affect roughly half of the adult population [3]. Due to serious complications, and the development of trophic ulcers in particular, this pathology adversely affects the patients' quality of life and places a heavy burden on the healthcare system [4].

The main objectives of the treatment for varicose veins include prevention of complications, alleviation of 
symptoms, and improvement of the patients' quality of life. The most common method of treatment for this condition is an open surgery proposed by W. Keller IIO years ago [5]. During a surgical procedure, the saphenofemoral junction is disconnected from the venous system via ligation in the case of the great saphenous vein disease or the saphenopopliteal junction is ligated in the case of the small saphenous vein damage. The ligation is usually followed by the great or the small saphenous vein removal (stripping).

The surgical intervention usually alleviates the symptoms and yields the desired results, yet sometimes the postoperative period is aggravated by the development of complications such as pain, bleeding, infection (inguinal or popliteal), thrombophlebitis, saphenous nerve damage, or impaired lymph drainage. Furthermore, the procedure leaves postoperative scars and there is a risk of hyperpigmentation [6]. Moreover, recurrent varicose veins are known to be a common problem after surgery: the literature demonstrates a recurrence rate of $60 \%$ after 5 years of follow-up observation $[7,8]$. The recurrence is mostly caused by neovascularisation, anatomic peculiarities (e.g. a double great saphenous vein), surgical technique errors, or an incomplete procedure [9].

The last decade has seen the emergence of minimally invasive methods of treatment for varicose veins, the endovenous laser ablation (EVLA) among them. EVLA is a percutaneous minimally invasive technique where a fibre laser is inserted under ultrasound guidance into the trunk of the affected vein. Within the lumen of the vein the energy generated by the laser produces temperature of up to $1000^{\circ} \mathrm{C}$ [10]. During EVLA, the walls of the vein are directly affected by the laser energy [II], heat [12], and steam bubbles [13], which results in venous wall microperforation due to the high temperature [14], eventually followed by shrinkage of the venous wall, complete subsequent scarification, and vein occlusion.

EVLA is a simpler and less complicated procedure [15]. The treatment requires only local rather than general or spinal anaesthesia. In addition, it can be done in a day surgery setting, which means that patients do not need to be hospitalised and they can sooner return to their normal life [16]. Moreover, laser ablation is associated with less postoperative pain, leaves no scars and may be applied in patients under anticoagulant therapy without the need to discontinue the treatment.

Some authors claim that EVLA is superior to the conventional open surgical treatment because it is not only as radical as an open surgery but it is also characterised by minimised tissue damage and thus a lower number of postoperative complications, a better index of the postoperative quality of life, a better cosmetic effect, and an earlier return to normal activity [17-19]. Although the procedure-related costs were found to be higher for EVLA than for conventional surgery [19, 20], EVLA has been identified as having the highest chance of being the most cost-effective method of treatment for varicose veins in the long term [21, 22].

Even though EVLA is increasingly popular and together with other minimally-invasive techniques is rapidly replacing surgical stripping, surgical treatment is still widely used.

Our study aimed to compare the clinical outcomes and the quality of life in patients with varicose veins of the lower limbs, who received endovenous laser ablation or open surgery.

\section{Material and methods}

\section{The studied population}

The prospective non-randomised study followed 299 patients, who in 2012 through 2013 were treated for symptomatic varicose veins of the lower limbs in two centres. In one, 159 patients underwent open surgery (the surgery group), while in the other, I 40 patients received an endovenous laser ablation (the EVLA group). The inclusion criteria were primary, symptomatic varicose veins with isolated saphenofemoral or saphenopopliteal junction incompetence and the great saphenous vein (GSV) or the small saphenous vein (SSV) reflux on duplex ultrasound imaging. The exclusion criteria were age under 18, CEAP clinical grades $\mathrm{CI}$, $\mathrm{C} 5$ or $\mathrm{C} 6$, pregnancy or breastfeeding, $1 \mathrm{II}^{\circ}$ obesity (BMI $>40 \mathrm{~kg} / \mathrm{m}^{2}$ ), arterial insufficiency or incompetence of the deep venous system. For all patients, the surgery involved only one leg. Where the same patient received surgery of the second leg within the study period, only the first leg was included into the study. Thus the number of patients in this study corresponds to the number of legs operated on.

The clinical and demographic characteristics of the patients are presented in Table I.

\section{Data collection and analysis}

The study protocol was approved by the Institutional Review Board of our hospital. Patients who were found eligible for the study were asked to sign a written consent to participate in the study. Prior to the surgery, patients' demographic data (sex, age at the time of the treatment, and BMI) were collected, the clinical grade according to the CEAP classification was determined, and the vein (the great saphenous vein [GSV] or the small saphenous vein [SSV]) to be surgically treated was recorded.

The severity of the symptoms was evaluated using the Venous Clinical Severity Score (VCSS). This is an 
Table I. Clinical and demographic characteristics of patients in the study group

\begin{tabular}{|c|c|c|c|}
\hline & Conventional surgery $(N=159)$ & $\operatorname{EVLA}(N=140)$ & $\mathbf{p}$ \\
\hline \multicolumn{4}{|l|}{ Age (years) } \\
\hline Mean & $5 \mathrm{I} . \mathrm{I}(\mathrm{SD} \mid 2.6)$ & $50.2(\mathrm{SD} \mid 3.9)$ & 0.106 \\
\hline Range & $21-73$ & $19-80$ & \\
\hline Sex, males / females & 51 (32.1\%) / 108 (67.9\%) & $32(22.9 \%) / 108$ (77.1\%) & 0.076 \\
\hline \multicolumn{4}{|l|}{ BMI $\left[\mathrm{kg} / \mathrm{m}^{2}\right]$} \\
\hline Mean & 28 (SD 5.3) & 26.7 (SD 5) & 0.068 \\
\hline Range & $16.4-39.8$ & $16.3-38.1$ & \\
\hline Obesity (BMI > 30 kg/m²) & $58(36.5 \%)$ & $35(25 \%)$ & 0.032 \\
\hline \multicolumn{4}{|l|}{ Operated vein } \\
\hline Great saphenous vein & $13 \mid(82.4 \%)$ & $106(75.7 \%)$ & 0.155 \\
\hline Small saphenous vein & $21(13.2 \%)$ & $25(17.9 \%)$ & 0.267 \\
\hline Both & $7(4.4 \%)$ & $9(6.4 \%)$ & 0.435 \\
\hline \multicolumn{4}{|l|}{ CEAP clinical grade } \\
\hline $\mathrm{C} 2$ & $20(11.8 \%)$ & $76(51.7 \%)$ & $<0.001$ \\
\hline C3 & $100(58.8 \%)$ & $43(29.3 \%)$ & $<0.001$ \\
\hline C4 & $39(22.9 \%)$ & $21(14.3 \%)$ & 0.040 \\
\hline Baseline VCSS (median) & 5 (IQR 3-7) & 5 (IQR 2.5-6) & 0.728 \\
\hline Baseline AVVQ (median) & I6.I (IQR 9.5-2I) & I5.6 (IQR 8.6- 19.5) & 0.270 \\
\hline
\end{tabular}

IQR — interquartile range; SD — standard deviation

instrument based on the evaluation of nine main symptoms of the disease: pain, varicose veins, venous oedema, skin pigmentation, inflammation, induration, and ulcers (duration, number, and size of active ulcers) [23]. The VCSS-based evaluation was conducted by a consulting vascular surgeon. The total score ranges from 0 (represents no significant venous disease) to 30 (maximum).

Before the study, the patients were also asked to fill out the Aberdeen Varicose Veins Questionnaire (AVVQ). This questionnaire consists of 13 items allowing for a detailed evaluation of the symptoms of chronic venous insufficiency. The AVVQ evaluation includes both symptoms (pain and itching) and clinical signs (oedema, hyperpigmentation, and ulceration). The questionnaire also includes questions related to the effect of the disease on the patient's quality of life, which is highly important in the contemporary studies in the field of phlebology [24]. The total score of the questionnaire ranges from 0 (no effect on the quality of life) to 100 (a maximum effect).

The postoperative complications were grouped into: I) minor, which do not require hospitalisation; and 2) major, which cause long-term adverse effects or death, and require hospitalisation and treatment.

Postprocedural pain scores and the intake of analgesics were evaluated during the first seven days after the procedure at the end of the day. Pain scores were taken by the patient with the help of a $10-\mathrm{cm}$ visual analogue scale $(0-$ no pain, $10-$ the greatest pain). In addition, the time needed to return to normal activity and work was also registered.

\section{Interventions}

All patients were marked before the surgery or EVLA using guidance by duplex ultrasonography.

An open surgery was performed under general or spinal anaesthesia. Depending on whether the trunk of the GSV or the SSV was affected, usually either the saphenofemoral or saphenopopliteal junction was ligated and the respective trunk was stripped.

EVLA was performed under perivenous tumescent anaesthesia with $0.05 \%$ lidocaine. The mean volume of applied tumescence fluid was $425 \mathrm{~mL}$ (SD 105; range $250-575$ ) when cooled solution was used, and $225 \mathrm{~mL}$ (SD 75; range 200-425) when warm solution was used. The procedure started with a percutaneous insertion of a 19-G needle into the affected venous trunk under ultrasound guidance. Subsequently, a guidewire was passed through the needle to the site of the saphenofemoral or saphenopopliteal junction. Then the needle was removed, and a 5-Fr catheter was inserted over the guidewire. Finally, the guidewire was removed and an optical fibre was inserted approximately $\mathrm{I}-2 \mathrm{~cm}$ distal from the saphenofemoral or saphenopopliteal junction. The laser energy was obtained by applying 
Table 2. EVLA treatment data for great saphenous vein (GSV) and small saphenous vein (SSV) ablation. The data are presented as mean (range)

\begin{tabular}{|c|c|c|}
\hline & GSV $(N=106)$ & $\operatorname{SSV}(\mathbf{N}=25)$ \\
\hline $\begin{array}{l}\text { Length of ablated } \\
\text { vein }[\mathrm{cm}]\end{array}$ & $36(3-90)$ & $21(3-40)$ \\
\hline $\begin{array}{l}\text { Diameter of ablated } \\
\text { vein }[\mathrm{mm}]\end{array}$ & $9.1(5-28)$ & $7.1(5-23)$ \\
\hline $\begin{array}{l}\text { Total energy } \\
\text { delivery [J] }\end{array}$ & $\begin{array}{c}2569 \\
(420-5040)\end{array}$ & $\begin{array}{c}1512 \\
(350-2898)\end{array}$ \\
\hline Energy density $[\mathrm{J} / \mathrm{cm}]$ & $\begin{array}{c}74.5 \\
(38.2-132.5)\end{array}$ & $\begin{array}{c}75 \\
(35-117.4)\end{array}$ \\
\hline
\end{tabular}

a I470-nm diode laser generator probe with a radial-tip fibre (Ceralas E, Biolitec, Jema, Germany). A 400-micron fibre and the power of $6 \mathrm{~W}$ was used for ablation of small diameter veins $(6-7 \mathrm{~mm})$, while a 600-micron fibre and the power of $10 \mathrm{~W}$ was used in cases of bigger diameter veins. Our protocol totally delivered $7 \mathrm{~J} \times$ diameter of vein $(\mathrm{mm})$ of laser energy per $\mathrm{cm}$ of treated vein. During the infrapopliteal ablation procedure, the amount of energy was modified by the time of exposure according to the diameter of the vein. EVLA treatment data are given in Table 2.

In both patient groups, the varicosities and incompetent perforators in the thigh and/or the calf were removed by performing mini-phlebectomies via stab incisions over varicose tributaries, which were avulsed using a vein hook or a Kocherised mosquito clamp.

The mean duration of surgery was 62.5 (SD I4. I; range 25-90) minutes, while EVLA lasted for 55.6 (SD I 2.8; range $20-75)$ minutes $(p=0.148)$.

\section{Postoperative care}

The postoperative management was the same for both groups. After the procedure, a non-stretch compression bandage was applied on patient's leg. After 48 hours, the patient removed the bandage and continued using an elastic class II compression stocking during the day only for at least one week after the operation. On the day of surgery 2500 to $3500 \mathrm{IU}$ of bemiparin was administered subcutaneously for the prevention of deep vein thrombosis. All patients were advised to mobilise immediately after the treatment. In addition, the patients were administered analgesics for pain management postoperatively.

\section{Follow-up}

The patients were invited to follow-up evaluations by a vascular surgeon at six weeks, one year, and two years after the surgery. The evaluation included patient examination, clinical examination, assessment of the
VCSS, the overall satisfaction with the operation, and disease recurrence. Patient's satisfaction was assessed by asking whether the patient would agree to undergo same intervention again if necessary, or recommend it to a friend. Clinical recurrence was defined as new varicose tributaries at least $3 \mathrm{~mm}$ in diameter arising after treatment.

During the follow-up evaluations, the patients filled out the AVV questionnaire again. Some of the patients either could not or refused to arrive for follow-up evaluation and thus they were interviewed in great detail via telephone. A complete follow-up was available for all the patients at six weeks. However, at one and two years after the treatment, 92 patients ( 38 and 54, respectively) were lost to follow-up and thus a total of 207 (I I I patients (69.8\%) in surgery group and 96 patients (68.6\%) in EVLA group) were followed until the end of the study.

\section{Statistical analysis}

Statistical analysis was performed using SPSS 22.0 software package (IBM, Armonk, New York, USA). Normality of data was checked by the Kolmogorov-Smirnov test. Normally distributed data are presented as mean together with standard deviation (SD) and compared with paired and unpaired Student's t-tests. Non-parametric data are presented as median together with interquartile range (IQR) and compared using the Mann-Whitney $U$ test for unrelated samples and the Wilcoxon signed ranks test for paired data. Categorical variables were compared using chi-square $\left(\chi^{2}\right)$ and Fisher's exact test.

We considered $p$ values of less than 0.05 statistically significant.

\section{Results}

\section{Disease-specific quality of life (Aberdeen Varicose Vein Questionnaire)}

Compared with the baseline scores, at one and two years after the treatment the improvement in the AWV scores was statistically significant in both patient groups $(p<0.001)$. At baseline, the AVVQ scores did not show a statistically significant difference between the surgery and the EVLA groups. However, six weeks after the treatment, statistically significantly lower AVVQ scores were observed in the EVLA group $(p<0.00 \mathrm{I})$. At one year after the treatment the results were reversed: statistically significantly lower AVVQ scores and better disease-specific quality of life (QoL) were observed in the surgery group $(p<0.00 \mathrm{I})$. At two years after the surgery, the results remained the same as one year before, i.e. statistically significantly lower AVVQ scores were found in the surgery group $(p=0.00 \mathrm{I})$. 
Table 3. AVQ results in patients with different clinical grades of CEAP classification at different time intervals after the treatment. Also AVVQ results in patients with GSV or SSV procedure. The data are presented as median (IQR)

\begin{tabular}{|c|c|c|c|c|c|c|}
\hline & \multicolumn{2}{|c|}{6 weeks } & \multicolumn{2}{|c|}{ I year } & \multicolumn{2}{|c|}{2 years } \\
\hline & Avve & $p$ & AVve & $p$ & Avve & $p$ \\
\hline $\begin{array}{l}\text { C2 } \\
\text { Surgery } \\
\text { EVLA }\end{array}$ & $\begin{array}{l}9.2(7.4-13) \\
2.6(1.3-3.8)\end{array}$ & $<0.001$ & $\begin{array}{c}\text { I.3 }(0.6-5.6) \\
\text { I.3(0-4.3) }\end{array}$ & SN & $\begin{array}{l}\text { I.3 }(0-7.8) \\
2.1(0-6.9)\end{array}$ & SN \\
\hline $\begin{array}{l}\text { C3 } \\
\text { Surgery } \\
\text { EVLA }\end{array}$ & $\begin{array}{c}8.4(4.3-11.9) \\
2.6(2.2-5.3)\end{array}$ & $<0.001$ & $\begin{array}{c}0(0-2.9) \\
5.2(1.3-7.2)\end{array}$ & $<0.001$ & $\begin{array}{c}0.6(0-3.6) \\
3.3(1.1-7.5)\end{array}$ & $<0.001$ \\
\hline $\begin{array}{l}\text { C4 } \\
\text { Surgery } \\
\text { EVLA }\end{array}$ & $\begin{array}{l}13(8.9-20) \\
8.7(6.8-19)\end{array}$ & 0.007 & $\begin{array}{c}1.3(0-2.6) \\
6.2(3.8-7.5)\end{array}$ & 0.018 & $\begin{array}{l}1.3(0-6.6) \\
6(0-11.8)\end{array}$ & 0.024 \\
\hline $\begin{array}{l}\text { GSV } \\
\text { Surgery } \\
\text { EVLA }\end{array}$ & $\begin{array}{c}9.2(7.1-12.1) \\
2.6(2.1-6.9)\end{array}$ & $<0.001$ & $\begin{array}{l}0(0-2.25) \\
1.9(0-6.6)\end{array}$ & 0.027 & $\begin{array}{c}1.7(0-4.3) \\
4.8(0.2-8.7)\end{array}$ & $<0.001$ \\
\hline $\begin{array}{l}\text { SSV } \\
\text { Surgery } \\
\text { EVLA }\end{array}$ & $\begin{array}{c}9.6(5.1-18.3) \\
6(1.3-12.2)\end{array}$ & 0.012 & $\begin{array}{c}0(0-2.6) \\
2.6(0-5.5)\end{array}$ & 0.045 & $\begin{array}{c}0(0-0.6) \\
3.1(1.4-|| .5)\end{array}$ & 0.002 \\
\hline $\begin{array}{l}\text { All patients } \\
\text { Surgery } \\
\text { EVLA }\end{array}$ & $\begin{array}{c}9.2(7.1-13.8) \\
3.2(2.1-8)\end{array}$ & $<0.001$ & $\begin{array}{l}0(0-2.25) \\
2.3(0-6.6)\end{array}$ & $<0.001$ & $\begin{array}{c}\text { I }(0-4.3) \\
2.4(0.2-6.8)\end{array}$ & 0.001 \\
\hline
\end{tabular}

SN — statistically not significant; GSV — great saphenous vein; SSV — small saphenous vein

Table 3 shows the AVVQ scores over different periods of treatment and with different CEAP clinical grades.

\section{Venous Clinical Severity Score}

Compared with the baseline scores, at one and two years after the treatment the VCSS scores statistically significantly improved in both patient groups $(p<0.00 \mathrm{I})$. At baseline, there was no difference in the VCSS scores between the analysed groups. Six weeks after the treatment, the VCSS score in the surgery group was statistically significantly $(p<0.00 \mathrm{I})$ higher. However, at one and two years after the intervention the VCSS scores converged and the difference between the groups was no longer statistically significant. Table 4 presents the VCSS scores during different periods of treatment and with different CEAP clinical grades.

\section{Complications}

In total, 20 (14.3\%) patients in the EVLA group and $35(22 \%)$ patients in the surgery group developed minor complications during the first six weeks $(p=0.085)$. Haematomas were more common in the surgery group, while discoloration occurred more frequently in patients of the EVLA group. The rates of minor complications which occurred in the first six weeks after both methods of treatment are presented in Table 5. During the study period, neither group of patients experienced deep vein thrombosis, skin necrosis or other major complications.

\section{Early postoperative pain and analgesia use}

Better results of early disease-specific QoL in EVLA group were also reflected by less reported postoperative pain compared with patients in the surgery group (Fig. I). As a result of this, a higher proportion of patients in the surgery group required supplementary analgesic drugs during the first week after the procedure $(p=0.007)$.

\section{Return to work and normal activities}

The median duration of time needed to return to normal activities after the treatment was 14 days (range $5-25$ ) in the surgery group and four days (range I-14) in the EVLA group $(p<0.00 \mathrm{I})$. Employed patients in the EVLA group also managed to return to work sooner than patients in the surgery group ( 14 days (range $5-30$ ) vs. 5 days (range I -30 ); $p<0.00 \mathrm{I}$ ).

\section{Clinical recurrence}

The analysis of clinical recurrence did not yield any statistically significant results. After one year the 
Table 4. VCSS results in patients with different clinical grades of CEAP classification at different time intervals after the treatment. Also VCSS results in patients with GSV or SSV procedure. The data are presented as median (IQR)

\begin{tabular}{|c|c|c|c|c|c|c|}
\hline & & & & & 2 ye & \\
\hline & vess & $\mathbf{p}$ & vess & $p$ & VCSS & $\mathbf{p}$ \\
\hline C2 & & & & & & \\
\hline Surgery & $4.5(4-5)$ & $<0.001$ & $0(0-2)$ & SN & $2(0.75-4)$ & SN \\
\hline EVLA & $0(0-I)$ & & $0(0-2)$ & & $2(0-2)$ & \\
\hline C3 & & & & & & \\
\hline Surgery & $4(2.5-6)$ & $<0.001$ & $0(I-2)$ & SN & $0(I-2.5)$ & SN \\
\hline EVLA & $0(0-1)$ & & $0(I-2)$ & & $0(1-2.5)$ & \\
\hline C4 & & & & & & \\
\hline Surgery & $5.5(3.8-8.5)$ & 0.038 & $I(I-2)$ & 0.014 & I $(0-4.5)$ & SN \\
\hline EVLA & $2(1.5-5)$ & & $5(0-6.5)$ & & $2(0-5)$ & \\
\hline GSV & & & & & & \\
\hline Surgery & $4(3-6)$ & $<0.001$ & $I(0-2)$ & SN & $I(0-3)$ & SN \\
\hline EVLA & $0.5(0-1.75)$ & & $I(0-2)$ & & $2(0-2.75)$ & \\
\hline SSV & & & & & & \\
\hline Surgery & $5(4-7.5)$ & $<0.001$ & $0.5(0-2)$ & SN & $0.5(0-1.3)$ & SN \\
\hline EVLA & $2(0-3.5)$ & & $0.5(0-2)$ & & I $(0.3-6.3)$ & \\
\hline All patients & & & & & & \\
\hline Surgery & $4(3-6)$ & $<0.001$ & I $(0-2)$ & SN & $I(0-3)$ & SN \\
\hline EVLA & I $(0-2)$ & & $I(0-2)$ & & $I(0-2)$ & \\
\hline
\end{tabular}

SN — statistically not significant; GSV — great saphenous vein; SSV — small saphenous vein

Table 5. The rates of minor complications which occurred in the first six weeks after EVLA and conventional surgery

\begin{tabular}{|c|c|c|c|}
\hline Complication & $\begin{array}{c}\text { EVLA }(N=140) \\
\text { No. }(\%)\end{array}$ & $\begin{array}{c}\text { Conventional surgery }(\mathbf{N}=159) \\
\text { No. }(\%)\end{array}$ & $p$ \\
\hline Symptomatic phlebitis & $5(3.6 \%)$ & $7(4.4 \%)$ & 0.711 \\
\hline Bruising & $2(1.4 \%)$ & $3(1.9 \%)$ & 0.757 \\
\hline Hematoma & $2(1.4 \%)$ & $10(6.3 \%)$ & 0.032 \\
\hline Discoloration & $6(4.3 \%)$ & $\mathrm{I}(0.6 \%)$ & 0.037 \\
\hline Infection & $\mathrm{I}(0.7 \%)$ & $4(2.5 \%)$ & 0.226 \\
\hline Sensory disturbance (e.g. paraesthesias) & $4(2.9 \%)$ & $10(6.3 \%)$ & 0.162 \\
\hline
\end{tabular}

condition recurred in $5.2 \%(n=5)$ of the patients in the EVLA group and in $4.5 \%(n=5)$ of the patients in the surgery group $(p=0.810)$. The recurrence rates at two years after the intervention were $14.6 \%(n=14)$ in the EVLA group and $13.5 \%(n=15)$ in the surgery group $(p=0.826)$.

\section{Overall satisfaction}

At two years after the intervention $88.5 \%(n=85)$ of the patients in the EVLA group and $94.6 \%(n=105)$ of the patients in the surgery group claimed that they would choose the same technique if they needed such treatment again or would recommend this technique to others $(p=0.114)$.

\section{Secondary procedures}

At one year after the treatment six patients in the EVLA group required secondary interventions: two patients needed surgical treatment (phlebectomy) and four patients chose aesthetic procedures (sclerotherapy of reticular veins and telangiectasias). Meanwhile, in the surgery group the need for secondary procedures 


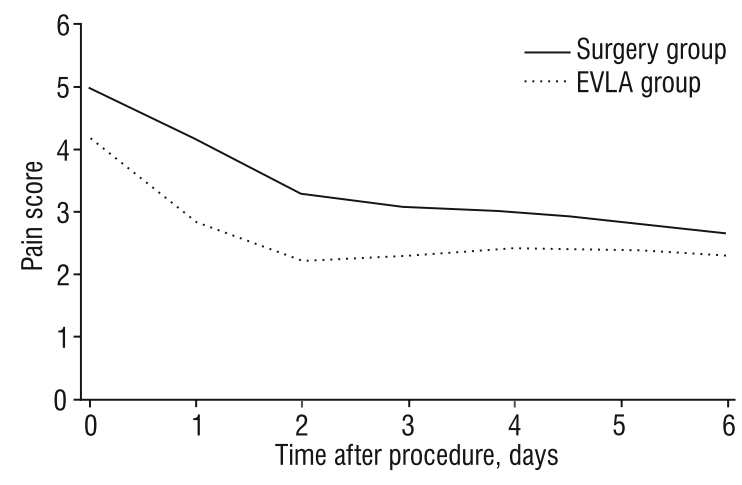

Figure I. Mean postoperative pain score (using a visual analogue scale) during the first seven days after EVLA and conventional surgery. The difference between the curves was statistically significant $(p<0.00$ I)

arose in four patients: two patients needed surgical treatment and two chose aesthetic procedures. A year later, nine patients in the EVLA group received additional procedures: two EVLA, four aesthetic procedures, and three phlebectomies. At two years after the treatment, six patients in the surgery group required additional interventions: three phlebectomies and three aesthetic treatments. In total, at two years after the initial treatment, additional interventions were chosen by 15 patients $(15.6 \%)$ in the EVLA group and 10 patients $(9 \%)$ in the surgery group $(p=0.144)$.

\section{Discussion}

Results obtained in our study confirm that EVLA is not only as effective as surgical stripping but also provides significantly better quality of life during the early post-treatment period and earlier return to work and normal activities.

In our study, 6 weeks after the treatment, statistically significantly lower AVVQ scores in all CEAP clinical grades were observed in the EVLA group. This shows that during the short postoperative period disease-specific quality of life was better after EVLA. At one and two years after the treatment better AVVQ scores were found in the surgery group. In a randomised controlled study [2I] conducted in 2015, which included 294 patients in the surgery group and 212 patients in the EVLA group, no statistically significant differences in the AVVQ scores between the EVLA and the surgery groups were found six weeks or six months after the treatment. A study by Mekako et al. [18] yielded similar results to those obtained in our study, i.e. a better disease-specific QoL in the EVLA group 6 and 12 weeks after treatment. So far there have been few studies analysing the AVVQ in different CEAP clinical grades. The results of our study showed that in clinical class $\mathrm{C} 2$, at one and two years after the initial treatment the AVVQ scores did not differ statistically significantly between the surgery and the EVLA groups. Meanwhile, at one and two years after the intervention in classes $\mathrm{C} 3$ and $\mathrm{C} 4$ statistically significantly better results were observed in the surgery group.

Most of the studies described in the literature indicate that after the treatment the clinical symptoms decrease equally statistically significantly and no difference in the VCSS between the surgery and the EVLA groups is found [20, 2I, 25-29]. In this study, six weeks after the treatment statistically significantly lower VCSS scores in all CEAP clinical grades were observed in the EVLA group. At one and two years after the intervention the treatment results in the groups converged and the difference was no longer statistically significant. The only exception was the $\mathrm{C} 4$ clinical group, where at one year after the treatment the VCSS scores were better in the surgery group.

In literature clinical recurrence at two years after the initial intervention ranges between $7 \%$ and $37 \%$ in the surgery group, and between $7 \%$ and $26 \%$ in the EVLA group $[28,30]$. In our study, at two years after the initial treatment the clinical recurrence rate in the EVLA group and the surgery group was $14.6 \%$ and $13.5 \%$, respectively, yet the difference was not statistically significant. Most of the studies also found no statistically significant difference between the groups at one or two years after the treatment [28, 30-32]. Carradice et al. [33] found the clinical recurrence rate at one year to be lower after EVLA than after surgery $(p<0.00 \mathrm{I})$. Theivacumar et al. [30] did not find any statistically significant difference in clinical recurrence between the groups at two years after the treatment, although neovascularization was detected in $18 \%$ of the surgery group patients compared to only $1 \%$ of the EVLA group patients $(p<0.00 \mathrm{I})$. The results of a randomised controlled trial [29] conducted in 2013 showed no difference in recurrence rates at five years after the initial treatment.

Concerning the patients' overall satisfaction with the treatment, the available studies do not present any statistically significant results $[25,30,34,35]$. Although in our study a slightly higher percentage of patients who received open surgery claimed that they would choose the same technique again or would recommend it to their relatives or friends, the difference between the surgery and the EVLA groups was not statistically significant. Furthermore, we can assume that the patient's overall satisfaction was also influenced by the fact that in Lithuania EVLA is not yet fully compensated by the National Health Insurance Fund, therefore patients likely had higher expectations for this procedure. 
In this study, several potential limitations merit consideration. First, our study was non-randomised; as a result there were some differences between study groups at baseline (number of obese patients, proportions of CEAP clinical grades). Moreover, EVLA and open conventional surgeries were performed in different centres, also, open surgeries were done by several different vascular surgeons. Furthermore, we included patients with both SSV and GSV disease in our analysis.

\section{Conclusions}

Both techniques - EVLA and surgery - yielded similar results in terms of efficacy, clinical recurrence rates and overall patient satisfaction. Although in the present study we did not find EVLA to be superior to surgical stripping in the long term, during the short postoperative period, results in the EVLA group were significantly better than those of the surgery group. Therefore, we assume that EVLA should be recommended over surgical stripping, especially for patients who find good quality of life during the early post-treatment period and early return to work and normal activity important.

\section{References}

I. Staffa R (2002) Chronic venous insufficiency-epidemiology. Bratisl Lek Listy; 103: 166-168.

2. Evans CJ, Fowkes FG, Ruckley CV, Lee AJ (1999) Prevalence of varicose veins and chronic venous insufficiency in men and women in the general population: Edinburgh Vein Study. J Epidemiol Community Health; 53: 149-153.

3. Margolis DJ, Bilker W, Santanna J, Baumgarten M (2002) Venous leg ulcer: incidence and prevalence in the elderly. J Am Acad Dermatol; 46: 38I-386.

4. Kurz X, Kahn SR, Abenhaim L et al (1999) Chronic venous disorders of the leg: epidemiology, outcomes, diagnosis and management. Summary of an evidence-based report of the VEINES task force. Venous Insufficiency Epidemiologic and Economic Studies. Int Angiol; 18: 83-102.

5. Keller W (1905) A new method of extirpating the internal saphenous and similar veins in varicose conditions: a preliminary report. New York Med J; 82: 385-386.

6. Critchley G, Handa A, Maw A, Harvey A, Harvey MR, Corbett CR (1997) Complications of varicose vein surgery. Ann R Coll Surg Engl; 79: 105-II0.

7. Beebe-Dimmer JL, Pfeifer JR, Engle JS, Schottenfeld D (2005) The epidemiology of chronic venous insufficiency and varicose veins. Ann Epidemiol; 15: 175-184.

8. Robertson L, Evans C, Fowkes FGR (2008) Epidemiology of chronic venous disease. Phlebology; 23: 103-1II.

9. Van Rij AM, Jiang P, Solomon C, Christie RA, Hill GB (2003) Recurrence after varicose vein surgery: a prospective long-term clinical study with duplex ultrasound scanning and air plethysmography. J Vasc Surg; 38: 935-943.
10. Disselhoff BCVM, Rem Al, Verdaasdonk RM, Kinderen DJ Der, Moll FL (2008) Endovenous laser ablation: an experimental study on the mechanism of action. Phlebology; 23: 69-76.

I I. Mordon SR, Wassmer B, Zemmouri J (2007) Mathematical modeling of $980-\mathrm{nm}$ and $1320-\mathrm{nm}$ endovenous laser treatment. Lasers Surg Med; 39: 256-265.

12. Van den Bos RR, Kockaert MA, Neumann HAM, Bremmer RH, Nijsten T, van Gemert MJC (2009) Heat conduction from the exceedingly hot fiber tip contributes to the endovenous laser ablation of varicose veins. Lasers Med Sci; 24: 247-25I.

13. Proebstle TM, Lehr HA, Kargl A et al (2002) Endogenous treatment of the greater saphenous vein with a $940-\mathrm{nm}$ diode laser: Thrombotic occlusion after endoluminal thermal damage by laser-generated steam bubbles. J Vasc Surg; 35: 729-736.

14. Weiss RA (2002) Comparison of endovenous radiofrequency versus $810 \mathrm{~nm}$ diode laser occlusion of large veins in an animal model. Dermatologic Surg; 28: 56-61.

15. Navarro L, Min RJ, Bone C (200I) Endovenous laser: a new minimally invasive method of treatment for varicose veins-preliminary observations using an $810 \mathrm{~nm}$ diode laser. Dermatol Surg; 27: 117-122.

16. Rautio T, Ohinmaa A, Perala J et al (2002) Endovenous obliteration versus conventional stripping operation in the treatment of primary varicose veins: a randomized controlled trial with comparison of the costs. J Vasc Surg; 35: 958-965.

17. De Medeiros CAF, Luccas GC (2005) Comparison of endovenous treatment with an $810 \mathrm{~nm}$ laser versus conventional stripping of the great saphenous vein in patients with primary varicose veins. Dermatol Surg; 31: 1685-1694.

18. Mekako Al, Hatfield J, Bryce J, Lee D, McCollum PT, Chetter I (2006) A nonrandomised controlled trial of endovenous laser therapy and surgery in the treatment of varicose veins. Ann Vasc Surg; 20: $45 \mathrm{I}-457$.

19. Rasmussen LH, Bjoern L, Lawaetz M, Blemings A, Lawaetz B, Eklof B (2007) Randomized trial comparing endovenous laser ablation of the great saphenous vein with high ligation and stripping in patients with varicose veins: short-term results. J Vasc Surg; 46: 308-315.

20. Rasmussen LH, Lawaetz M, Bjoern L, Vennits B, Blemings A, Eklof B (20II) Randomized clinical trial comparing endovenous laser ablation, radiofrequency ablation, foam sclerotherapy and surgical stripping for great saphenous varicose veins. $\mathrm{Br} J$ Surg; 98: 1079-1087.

21. Brittenden J, Cotton SC, Elders A et al (2015) Clinical effectiveness and cost-effectiveness of foam sclerotherapy, endovenous laser ablation and surgery for varicose veins: results from the Comparison of LAser, Surgery and foam Sclerotherapy (CLASS) randomised controlled trial. Health Technol Assess (Rockv); 19: I-342.

22. Gohel MS, Epstein DM, Davies AH (2010) Cost-effectiveness of traditional and endovenous treatments for varicose veins. $\mathrm{Br} J$ Surg; 97: 1815-1823.

23. Vasquez MA, Rabe E, McLafferty RB et al (2010) Revision of the venous clinical severity score: venous outcomes consensus statement: special communication of the American Venous Forum Ad Hoc Outcomes Working Group. J Vasc Surg; 52: 1387-1396.

24. Carradice D, Mazari FAK, Samuel N, Allgar V, Hatfield J, Chetter IC (20II) Modelling the effect of venous disease on quality of life. Br J Surg; 98: 1089-1098. 
25. Darwood RJ, Theivacumar N, Dellagrammaticas D, Mavora ID, Gough MJ (2008) Randomized clinical trial comparing endovenous laser ablation with surgery for the treatment of primary great saphenous varicose veins. Br J Surg; 95: 294-30I.

26. Samuel N, Carradice D, Wallace T, Mekako A, Hatfield J, Chetter I (2013) Randomized clinical trial of endovenous laser ablation versus conventional surgery for small saphenous varicose veins. Ann Surg; 257: 419-426.

27. Christenson JT, Gueddi S, Gemayel G, Bounameaux H (2010) Prospective randomized trial comparing endovenous laser ablation and surgery for treatment of primary great saphenous varicose veins with a 2-year follow-up. J Vasc Surg; 52: 1234-124I.

28. Rasmussen LH, Bjoern L, Lawaetz M, Lawaetz B, Blemings A, Eklof $B(2010)$ Randomised clinical trial comparing endovenous laser ablation with stripping of the great saphenous vein: clinical outcome and recurrence after 2 years. Eur J Vasc Endovasc Surg; 39: 630-635.

29. Rasmussen L, Lawaetz M, Bjoern L, Blemings A, Eklof B (2013) Randomized clinical trial comparing endovenous laser ablation and stripping of the great saphenous vein with clinical and duplex outcome after 5 years. J Vasc Surg; 58: 42I-426.

30. Theivacumar NS, Darwood R, Gough MJ (2009) Neovascularisation and Recurrence 2 Years After Varicose Vein Treatment for Sapheno-Femoral and Great Saphenous Vein Reflux: A Com- parison of Surgery and Endovenous Laser Ablation. Eur J Vasc Endovasc Surg; 38: 203-207.

31. Rass K, Frings N, Glowacki P et al (2012) Comparable effectiveness of endovenous laser ablation and high ligation with stripping of the great saphenous vein: two-year results of a randomized clinical trial (RELACS study). Arch Dermatol; I48: 49-58.

32. Pronk P, Gauw S a, Mooij MC et al (2010) Randomised controlled trial comparing sapheno-femoral ligation and stripping of the great saphenous vein with endovenous laser ablation (980 $\mathrm{nm}$ ) using local tumescent anaesthesia: one year results. Eur J Vasc Endovasc Surg; 40: 649-656.

33. Carradice D, Mekako I, Mazari FK, Samuel N, Hatfield J, Chetter IC (20I I) Clinical and technical outcomes from a randomized clinical trial of endovenous laser ablation compared with conventional surgery for great saphenous varicose veins. Br J Surg; 98: II I7-I I 23.

34. Kalteis M, Berger I, Messie-Werndl S et al (2008) High ligation combined with stripping and endovenous laser ablation of the great saphenous vein: early results of a randomized controlled study. J Vasc Surg; 47: 822-829; discussion 829.

35. Carradice D, Mekako a I, Mazari F a K, Samuel N, Hatfield J, Chetter IC (20II) Randomized clinical trial of endovenous laser ablation compared with conventional surgery for great saphenous varicose veins. $\mathrm{Br}$ J Surg; 98: 50I-510. 